University of Nebraska - Lincoln

DigitalCommons@University of Nebraska - Lincoln

$11-2006$

\title{
Plant Reproductive Allocation Predicts Herbivore Dynamics across Spatial and Temporal Scales
}

Tom E. X. Miller

University of Nebraska - Lincoln

Andrew J. Tyre

University of Nebraska - Lincoln, atyre2@unl.edu

Svata M. Louda

University of Nebraska - Lincoln, slouda1@unl.edu

Follow this and additional works at: https://digitalcommons.unl.edu/bioscifacpub

Part of the Life Sciences Commons

Miller, Tom E. X.; Tyre, Andrew J.; and Louda, Svata M., "Plant Reproductive Allocation Predicts Herbivore Dynamics across Spatial and Temporal Scales" (2006). Faculty Publications in the Biological Sciences. 55.

https://digitalcommons.unl.edu/bioscifacpub/55

This Article is brought to you for free and open access by the Papers in the Biological Sciences at DigitalCommons@University of Nebraska - Lincoln. It has been accepted for inclusion in Faculty Publications in the Biological Sciences by an authorized administrator of DigitalCommons@University of Nebraska - Lincoln. 


\title{
Plant Reproductive Allocation Predicts Herbivore Dynamics across Spatial and Temporal Scales
}

\author{
Tom E. X. Miller, ${ }^{1, *}$ Andrew J. Tyre, ${ }^{2, \dagger}$ and Svata M. Louda ${ }^{1, \ddagger}$
}

1. School of Biological Sciences, University of Nebraska, Lincoln, Nebraska 68588;

2. School of Natural Resources, University of Nebraska, Lincoln, Nebraska 68583

Submitted December 2, 2005; Accepted June 14, 2006;

Electronically published October 5, 2006

Online enhancements: appendixes.

ABSTRACT: Life-history theory suggests that iteroparous plants should be flexible in their allocation of resources toward growth and reproduction. Such plasticity could have consequences for herbivores that prefer or specialize on vegetative versus reproductive structures. To test this prediction, we studied the response of the cactus bug (Narnia pallidicornis) to meristem allocation by tree cholla cactus (Opuntia imbricata). We evaluated the explanatory power of demographic models that incorporated variation in cactus relative reproductive effort (RRE; the proportion of meristems allocated toward reproduction). Field data provided strong support for a single model that defined herbivore fecundity as a time-varying, increasing function of host RRE. High-RRE plants were predicted to support larger insect populations, and this effect was strongest late in the season. Independent field data provided strong support for these qualitative predictions and suggested that plant allocation effects extend across temporal and spatial scales. Specifically, late-season insect abundance was positively associated with interannual changes in cactus RRE over 3 years. Spatial variation in insect abundance was correlated with variation in RRE among five cactus populations across New Mexico. We conclude that plant allocation can be a critical component of resource quality for insect herbivores and, thus, an important mechanism underlying variation in herbivore abundance across time and space.

Keywords: demographic model, herbivory, insect-plant interactions, Opuntia, population dynamics, resource allocation.

\footnotetext{
* Corresponding author; e-mail: tmiller2@unl.edu.

E-mail: atyre2@unl.edu.

₹ E-mail: slouda@unl.edu.
}

Am. Nat. 2006. Vol. 168, pp. 608-616. (c) 2006 by The University of Chicago. 0003-0147/2006/16805-41473\$15.00. All rights reserved.
Life-history functions, such as plant growth and reproduction, typically incur physiological and demographic costs (Bazzaz and Grace 1997). Consequent trade-offs between functions are axiomatic to plant life-history theory (Harper 1977; Silvertown and Dodd 1999). Such theory predicts that iteroparous perennials-long-lived plants capable of repeated reproductive bouts-should be flexible in their relative allocation of resources to growth versus reproduction (Bonser and Aarssen 1996; Bazzaz and Grace 1997).

Resource allocation decisions can be quantified in the currency of meristems, the primordial tissues from which vegetative and reproductive organs arise (Geber 1990; Bonser and Aarssen 1996; Geber et al. 1997; Olejniczak 2001; Hartemink et al. 2004). The total number of active meristems available at a given time is finite, and once committed to a particular function, a meristem cannot be redirected to another function (Watson 1984). For nonclonal, iteroparous perennial plants, this can present an acute strategic dilemma. Allocation of meristems to current reproduction has the potential for immediate fitness benefits, but it constrains growth and, consequently, future reproductive potential. Conversely, the allocation of meristems to production of vegetative structures limits current reproductive output, but long-term gains in size, survival, and future fecundity could outweigh current losses (Geber 1990; Hartemink et al. 2004).

Meristem allocation strategies to cope with these tradeoffs can vary widely among species, among populations within species, among individuals within populations, and within individuals across time; such variation is consistent with theory and may be driven by genetic and/or environmental factors (Geber 1990; Bowers 1996; Duffy et al. 1999; Reekie 1999; Hartemink et al. 2004; Mendez and Karlsson 2004). These patterns lead to the prediction that variation in the production of vegetative versus reproductive parts should have consequences for herbivores that prefer or specialize on specific plant structures. Yet, plasticity in plant resource allocation has rarely been examined as a potential driver of variation in the abundance of higher 
trophic levels (Klinkhamer et al. 1997; Prado and Vieira 1999).

Evaluating the strength of this linkage is important because it may help explain the widespread spatial and temporal variation in herbivore abundance and damage observed both within and among host plant populations (e.g., Louda 1982, 1983; Denno and McClure 1983; Root and Cappuccino 1992; Root 1996; Bradley et al. 2003). The bottom-up factors that contribute to this variation in herbivory are potentially numerous (Crawley 1983, 1997; Underwood and Rausher 2000). For example, plant nutrient content (White 1984), water content (Huberty and Denno 2004), physical and chemical defenses (Rhoades 1983; Edelstein-Keshet and Rausher 1989; Larsson et al. 2000), and combinations of the above (Rausher 1981; Louda and Collinge 1992; Agrawal 2004) are known to influence herbivore performance, abundance, and dynamics. In contrast, the influence of host plant resource allocation has not been intensively examined in this context (but see Holland et al. 2004).

The goals of this study were to (1) evaluate the role of host plant resource allocation in the population dynamics of a specialist insect herbivore and (2) determine whether this plant trait can predict variation in insect abundance across broad temporal and spatial scales. We studied the interaction between the cactus bug (Narnia pallidicornis Stål [Hemiptera: Coreidae]) and the tree cholla cactus (Opuntia imbricata [Haw.] D.C.) in the Chihuahuan Desert of New Mexico. Narnia will feed on all cactus parts but prefer the reproductive structures (Mann 1969, 1970). Tree cholla cacti produce undifferentiated meristems on the ends of stem segments early in the growing season (Gibson and Nobel 1986), and the plant then must subsequently decide the fate of each (Bowers 1996). Tree cholla meristem allocation is variable within individuals across time and among individuals across space.

We developed a series of predictive, stage-structured models of herbivore population dynamics that incorporate variation in host plant resource allocation and fit the models to field data. We then evaluated the predictions of the most likely model using multiple independent data sets on plant allocation patterns and insect abundance spanning 3 years and five tree cholla populations across central New Mexico.

\section{Methods \\ Natural History of the Study Organisms}

The coreid bug Narnia pallidicornis specializes on Opuntia cacti (Mann 1969). There are two generations within a year, and juveniles and adults co-occur on cacti throughout the growing season. Adults overwinter among debris near the base of the plant, and females deposit eggs on cactus spines from March to May. The first cohort of nymphs reaches maturity in May-June, and the second, larger, cohort matures in August-September (Mann 1969). Juveniles are flightless and complete their development on a single host plant (Mann 1969). Early-season abundance on a plant is not correlated with late-season abundance from the previous year (data from 2003 to 2004: $n=$ $47, r=0.11, P=.47$ ), suggesting that Narnia dynamics at the single plant level are independent across adjacent years.

The tree cholla (Opuntia imbricata) is a perennial arborescent cactus, native to New Mexico, west Texas, and southern Colorado (Kinraide 1978; Benson 1982), that produces cylindrical stem segments. Early in the growing season (mid-May to early June in central New Mexico), meristems appear in clusters at the terminal ends of stem segments produced the previous year, and these develop into either reproductive or vegetative structures. Meristems allocated to reproduction develop into flower buds in late spring; the fruits ripen and fall off of plants in early fall. Meristems allocated to new stem segments grow from May to August and produce new meristems the following spring.

We quantified plant allocation as the proportion of total available meristems that developed into reproductive structures, which we call relative reproductive effort (RRE). This metric is bound by 0 and 1 , where a plant with $\mathrm{RRE}=0$ allocates all meristems to growth, a plant with RRE $=1$ allocates all meristems to reproduction, and a plant with $\mathrm{RRE}=0.5$ allocates equally between growth and reproduction. We focus on RRE rather than, for example, absolute numbers of reproductive structures for two important reasons. First, any variation in flower production among similarly sized plants ultimately must be driven by variable individual allocation strategies; our aim was to quantify these strategies and their consequences directly rather than their proxies or corollaries. Second, trade-offs between life-history functions assume a central role in current thinking about plant resource allocation (Bazzaz and Grace 1997; Obeso 2002). Because RRE explicitly accounts for such trade-offs, we think that this approach allows our results to be interpreted in light of, and integrated into, existing theory.

\section{Stage-Structured Insect Dynamics and Host Plant Allocation Effects}

We describe the per-plant dynamics of juvenile and adult cactus bugs with the following model structure: 


$$
\begin{aligned}
J_{t+\Delta t} & =s_{\mathrm{j}}(1-T) J_{t}+f\left(s_{\mathrm{a}} A_{t}+c\right), \\
A_{t+\Delta t} & =s_{\mathrm{j}} T J_{t}+s_{\mathrm{a}} A_{t}+c,
\end{aligned}
$$

where $J_{t}$ and $A_{t}$ are juvenile and adult bug abundances, respectively, at time $t ; s_{\mathrm{i}}$ and $s_{\mathrm{a}}$ are the survival probabilities of juveniles and adults, respectively; $T$ is the probability of transition from the juvenile to the adult stage; $f$ is adult realized fecundity (juveniles per adult); and $c$ is the adult colonization rate (adults per $\Delta t$ ). There are multiple time steps within a growing season (i.e., $\Delta t<1$ year), and this model structure assumes that juveniles cannot transition and reproduce within a single time step. Because juvenile bugs are flightless and complete development on single plants, there is no juvenile movement in the model. Because detecting eggs and differentiating among instars are difficult and time consuming in the field, the egg stage is not explicitly included in the model, and all immature stages are considered collectively in the juvenile class. The colonization parameter is density independent in order to account for midseason appearance of insects on previously unoccupied plants. Adult emigration also occurs (clearly, colonists are coming from somewhere), but it is implicitly incorporated into the model because emigration and mortality could not be differentiated in time series data. Thus $s_{\mathrm{a}}$ represents the joint probability of an adult surviving and remaining on a host plant to be detected at the next time step.

Using this basic structure, we examined the relative explanatory power of 16 models that incorporated realistic variation in the five demographic parameters (table 1). In these models, each parameter could take one of four forms. These were (1) constant across time and host plants, (2) unique to each time step (e.g., colonization: $c=c_{t}$ ), (3) unique to each host plant as a constant linear function of its RRE (e.g., $c=c \times \mathrm{RRE}$ ), and (4) unique to each host plant as a time-varying linear function of cactus RRE (e.g., $c=c_{t} \times \mathrm{RRE}$ ). Because resource quality changes over the season and because the probability of certain demographic events may vary with population age structure, we expected that the time-varying models would provide a better fit to field data.

Each of our candidate models (table 1) allows a single parameter to vary with time or with host allocation (as opposed to multiple parameters in combination). This approach allowed us to evaluate a broad range of demographic hypotheses while keeping the total number of models and the number of parameters in each relatively small. In this way, we focus on the issues of whether RRE influences insect dynamics and, if so, which demographic transition best explains an RRE effect rather than trying to differentiate the specific mechanics of such an effect.

\section{Data Collection and Model Fitting}

Data used to test the relative explanatory power of the competing models were collected during spring and summer 2004 in a Chihuahuan Desert grassland at the Sevilleta National Wildlife Refuge, a long-term ecological research (LTER) site in central New Mexico $\left(34^{\circ} 20^{\prime} 5.3^{\prime \prime} \mathrm{N}\right.$, $\left.106^{\circ} 37^{\prime} 53.2^{\prime \prime} \mathrm{W}\right)$. Annual precipitation at the study site averages $245 \mathrm{~mm} /$ year, most of which falls from July to September (Sevilleta LTER Program meteorological data, 1989-1999). In early May 2004, we located and tagged 80 mature tree cholla at the Sevilleta. Numbers of juvenile and adult Narnia on each plant were counted on five sampling dates 25-30 days apart: May 13-15, June 7-9, July $2-4$, July $24-26$, and August 16-18, 2004. Any eggs observed were not included in the juvenile counts. For each plant, we also counted the numbers of newly produced stem segments and flower buds in June and used these counts to calculate cactus RRE. These plants showed a wide range of meristem allocation strategies (minimum $\mathrm{RRE}=0$, maximum $\mathrm{RRE}=0.86$ ). Using sequential counts of stem segments from the most recent growth to the root crown, we estimated that these plants were $10.3 \pm 0.21$ (mean $\pm \mathrm{SE}$ ) years old at the time sampled. This method assumed no loss of segments and therefore provided a minimum age estimate.

We used maximum likelihood methods to confront the 16 candidate models with data (Hilborn and Mangel 1997) and Akaike's Information Criterion (AIC) to select the one with the most explanatory power (Burnham and Anderson 1998). We defined the model time step based on the schedule of data collection; that is, $\Delta t \approx 25$ days. This interval is greater than the duration of the egg stage (egg duration of a closely related cactus-feeding coreid is 12 days; Mann 1969), and so our estimate of fecundity (juveniles per adult) does not require a time lag in the model.

We first generated 16 season-wide projections of Narnia abundance on each plant, each corresponding to one of the models in table 1 , using the May sampling date as $t_{0}$. Projections at each subsequent time step were based on observed rather than predicted abundances; thus, the model included process error but not observation error (Hilborn and Mangel 1997). We considered the presence of an insect on a plant as a random event and used a natural log-transformed Poisson function, which gives the likelihood of each observation $(x)$, given the value predicted by the model $(\mu)$. We calculated the total negative log likelihood $(L)$ of each model by summing the likelihoods over all sampling dates $(t=1, \ldots, 4)$ and plants $(m=1, \ldots, 80)$ :

$$
L=\sum_{m=1}^{80} \sum_{t=1}^{4} \mu_{m t}-x_{m t} \ln \mu_{m t}+\ln \left(x_{m t} !\right) .
$$


Table 1: Candidate models of cactus bug (Narnia pallidicornis), population dynamics on tree cholla (Opuntia imbricata), and the results of model fitting to a subset of the field data

\begin{tabular}{lcccccccc}
\hline Model & $\begin{array}{c}\text { Adult } \\
\text { survival }\end{array}$ & $\begin{array}{c}\text { Juvenile } \\
\text { survival }\end{array}$ & Colonization & Fecundity & Transition & No. parameters & $\Delta$ AICc & $w_{i}$ \\
\hline 1 & $s_{\mathrm{a}}$ & $s_{\mathrm{j}}$ & $c$ & $f$ & $T$ & 5 & 586.96 & $3.5 \mathrm{E}-128$ \\
2 & $s_{\mathrm{a} t}$ & $s_{\mathrm{j}}$ & $c$ & $f$ & $T$ & 8 & 489.09 & $6.3 \mathrm{E}-107$ \\
3 & $s_{\mathrm{a}}(\mathrm{RRE})$ & $s_{\mathrm{j}}$ & $c$ & $f$ & $T$ & 5 & 460.94 & $8.1 \mathrm{E}-101$ \\
4 & $s_{\mathrm{at}}(\mathrm{RRE})$ & $s_{\mathrm{j}}$ & $c$ & $f$ & $T$ & 8 & 394.84 & $1.8 \mathrm{E}-86$ \\
5 & $s_{\mathrm{a}}$ & $s_{\mathrm{j}}$ & $c$ & $f$ & $T$ & 8 & 311.68 & $2.1 \mathrm{E}-68$ \\
6 & $s_{\mathrm{a}}$ & $s_{\mathrm{j}}(\mathrm{RRE})$ & $c$ & $f$ & $T$ & 5 & 526.18 & $5.5 \mathrm{E}-115$ \\
7 & $s_{\mathrm{a}}$ & $s_{\mathrm{j} t}(\mathrm{RRE})$ & $c$ & $f$ & $T$ & 8 & 414.20 & $1.1 \mathrm{E}-90$ \\
8 & $s_{\mathrm{a}}$ & $s_{\mathrm{j}}$ & $c_{t}$ & $f$ & $T$ & 8 & 544.95 & $4.6 \mathrm{E}-119$ \\
9 & $s_{\mathrm{a}}$ & $s_{\mathrm{j}}$ & $c(\mathrm{RRE})$ & $f$ & $T$ & 5 & 369.97 & $4.6 \mathrm{E}-81$ \\
10 & $s_{\mathrm{a}}$ & $s_{\mathrm{j}}$ & $c_{t}(\mathrm{RRE})$ & $f$ & $T$ & 8 & 284.21 & $1.9 \mathrm{E}-62$ \\
11 & $s_{\mathrm{a}}$ & $s_{\mathrm{j}}$ & $c$ & $f$ & $T$ & 8 & 240.25 & $6.8 \mathrm{E}-53$ \\
12 & $s_{\mathrm{a}}$ & $s_{\mathrm{j}}$ & $c$ & $f(\mathrm{RRE})$ & $T$ & 5 & 416.87 & $3.0 \mathrm{E}-91$ \\
$\mathbf{1 3}$ & $s_{\mathrm{a}}$ & $s_{\mathrm{j}}$ & $c$ & $f_{t}(\mathrm{RRE})$ & $T$ & $\mathbf{8}$ & $\mathbf{0 0}$ & $\mathbf{9 9}$ \\
14 & $s_{\mathrm{a}}$ & $s_{\mathrm{j}}$ & $c$ & $f$ & $T_{t}$ & 8 & 466.64 & $4.7 \mathrm{E}-102$ \\
15 & $s_{\mathrm{a}}$ & $s_{\mathrm{j}}$ & $c$ & $f$ & $T(\mathrm{RRE})$ & 5 & 582.99 & $2.5 \mathrm{E}-127$ \\
16 & $s_{\mathrm{a}}$ & $s_{\mathrm{j}}$ & $c$ & $f$ & $T_{t}(\mathrm{RRE})$ & 8 & 441.65 & $1.3 \mathrm{E}-96$ \\
\hline
\end{tabular}

Note: In these models, each parameter was constant, dependent on time, or dependent on host plant relative reproductive effort (RRE) as either a constant or a time-varying linear function. General model structure is shown in the text (eq. [1]). The table shows the functional form of the demographic parameters; the number of parameters in each model; the $\triangle \mathrm{AICc}$ value, which gives the difference between the Akaike's Information Criterion value adjusted for sample size (AICc) of each model and the lowest AICc of all models; and Akaike weights $\left(w_{i}\right)$, which give the proportional weight of evidence in favor of each model. We did not include intercepts in the models incorporating RRE. Models with such extra parameters either did not converge or led to biologically implausible values with large confidence limits for all parameters. Model 13, with host $\times$ time-dependent fecundity (shown in bold), is the most likely, given the data. See table 2 for maximum likelihood parameter estimates.

We minimized $L$ over all model parameters using the Solver feature in Microsoft Excel. The survival and transition probabilities were bound by 0 and 1 , and colonization rate and fecundity were constrained to be $\geq 0$ using logistic and exponential transformations, respectively. The constraint on colonization ensured positive predicted values of insect abundance ( $L$ is undefined for $\mu \leq 0$ ).

For each model, we calculated AIC, a parsimony-based statistic that imposes an increasing penalty on $L$ as the number of parameters increases. We then calculated AICc values and Akaike weights for each model according to equations given by Burnham and Anderson (1998). The AICc values are corrected for sample size ( $n=80$ plants), and Akaike weights can be interpreted as the proportion of evidence in favor of each model within a given set (Burnham and Anderson 1998). We did not use model averaging to make our predictions because the Akaike weight for the best model was substantively greater than all other models combined.

\section{Data Collected to Evaluate Model Predictions}

To evaluate qualitative model predictions for variation in insect abundance in relation to host plant resource allocation, we collected three additional, independent data sets on Narnia abundance and O. imbricata RRE across years and both local and regional spatial scales. First, we monitored an additional 117 O. imbricata cacti at the Sevilleta during summer 2004. These data were used to evaluate predictions among plants for the same site and year as the model fitting data. Second, a subset of these plants $(n=47)$ was also visited and measured twice during the previous year (2003) and twice the following year (2005). We used these observations to determine whether interannual variation in cactus bug abundance was associated with variation in tree cholla resource allocation. Because our model predicted within-season variation in host allocation effects (see "Results"), if an association occurred, we also asked whether it differed between early- and lateseason cohorts. Third, in 2004 we examined five O. imbricata populations along a south-north transect in central New Mexico (see map in fig. $2 B$ ) to determine whether large-scale spatial variation in Narnia abundance was associated with among-population variation in host plant RRE. Further information on data collection methods and statistical analyses is given in appendix $\mathrm{A}$ in the online edition of the American Naturalist.

\section{Results}

We used field data on cactus RRE and insect abundance to evaluate the explanatory power of 16 models of cactus 
bug population dynamics. We found that among-plant variation in cactus bug abundance was strongly predicted by host plant resource allocation. The model with the most explanatory power defined the fecundity parameter as a time-varying increasing function of host RRE (table 1, model 13). Akaike weights indicated that the field data strongly supported this over all other candidate models $\left(w_{13}=0.99\right)$. Thus, Narnia recruitment is greatest on plants that allocate proportionally more meristems toward reproduction than vegetative growth, either because adults lay more eggs or eggs and early juveniles have greater survival on these plants. Parameter estimates (table 2) indicated that this effect was greatest late in the growing season. Incorporating these estimates into the AIC-selected demographic model structure yielded per-plant projections of cactus bug abundance that show a strong effect of host plant resource allocation that increases over the growing season (fig. 1). Data used to fit the model are also shown in figure 1 according to low or high RRE, and these data are described well by the model.

We used three additional, independent data sets to evaluate temporal and spatial consistency of the model prediction that Narnia abundance is positively related to tree cholla RRE. First, we tracked cactus bug abundance on an additional set of tree cholla at the Sevilleta in 2004, and these independent data, also shown in figure 1, are described well by the AIC-selected model. For the subset of these plants that we tracked for 3 years, RRE differed significantly across years (fig. $2 A$ ). This pattern was mirrored by an increase in late-season cactus bug abundance across years, while early-season abundance increased only slightly across years (fig. 2A). Finally, we examined spatial variation using data from tree cholla populations examined along a south-north transect through central New Mexico in 2004. We found wide variation in resource allocation patterns among tree cholla populations (mean \pm SE RRE from $0.22 \pm 0.03$ to $0.48 \pm 0.029$ ). Across these populations, Narnia abundance was positively correlated with tree cholla RRE (fig. 2B).

\section{Discussion}

Variation in meristem allocation is widespread and critically important in long-term plant performance, yet plant allocation patterns have seldom been evaluated for their effects on insect herbivore abundance or dynamics. Here, we found that relative allocation of meristems to reproduction versus to vegetative growth had strong predictive ability across temporal and spatial scales for the cactus bug on tree cholla cacti. These results suggest that plant resource allocation is an important aspect of host plant quality for Narnia and that plant allocation can influence and
Table 2: Parameter estimates and 95\% confidence limits corresponding to the Akaike's Information Criterion-selected model structure (table 1, model 13)

\begin{tabular}{lc}
\hline Parameter & $\begin{array}{c}\text { Point estimate }(95 \% \\
\text { confidence limits })\end{array}$ \\
\hline Juvenile survival $\left(s_{\mathrm{j}}\right)$ & $.31(.24, .38)$ \\
Adult survival $\left(s_{\mathrm{a}}\right)$ & $.28(.24, .34)$ \\
Transition $(T)$ & $.16(.08, .25)$ \\
Colonization $(c)$ & $.86(.76, .97)$ \\
Fecundity $(f):$ & \\
$\quad$ May & $10.22(8.6,12.14) \times \mathrm{RRE}$ \\
$\quad$ June & $1.31(.84,1.93) \times \mathrm{RRE}$ \\
$\quad$ July & $9.04(7.76,10.56) \times \mathrm{RRE}$ \\
$\quad$ August & $18.39(15.92,21.29) \times \mathrm{RRE}$ \\
\hline
\end{tabular}

Note: $\mathrm{RRE}=$ relative reproductive effort.

help explain variation in herbivore abundance within and among plant populations.

The model of cactus bug population dynamics that best described our field data (table 1, model 13) predicted that greater allocation of meristems toward reproductive structures led to greater per-plant bug abundances and that this effect intensified from early to late in the growing season (fig. 1). The model identified fecundity (juveniles per adult) as the insect population parameter most responsive to plant allocation. There are at least two possible explanations for the temporal variation in parameter estimates that we observe (table 2). First, insect fecundity may be related to plant resource quality, which likely increases throughout the season as meristems differentiate (insect population growth begins before complete differentiation) and fruits ripen. Second, population age structure (within stage structure) could cause the time-dependent model to provide the best fit, independent of resource seasonality. For example, adults observed in the first census period had reached maturity the previous fall, whereas those observed at the second census had likely just matured from the first cohort of juveniles. Thus, any differences in fecundity between old and young adults could also drive temporal variation in parameter estimates. Our data do not allow us to distinguish between these possibilities, and the temporal variation in model structure is difficult to interpret with certainty.

Additional data, independent of those used for model fitting, supported the main model predictions of the importance of plant allocation. Increases in tree cholla RRE over 3 years coincided with significant increases in Narnia abundance that were greater for the late- than early-season cohorts (fig. 2A), as predicted. Spatially, tree cholla populations that, on average, allocated proportionally more meristems toward reproduction supported larger cactus bug populations (fig. $2 B$ ), as predicted. It is important to 


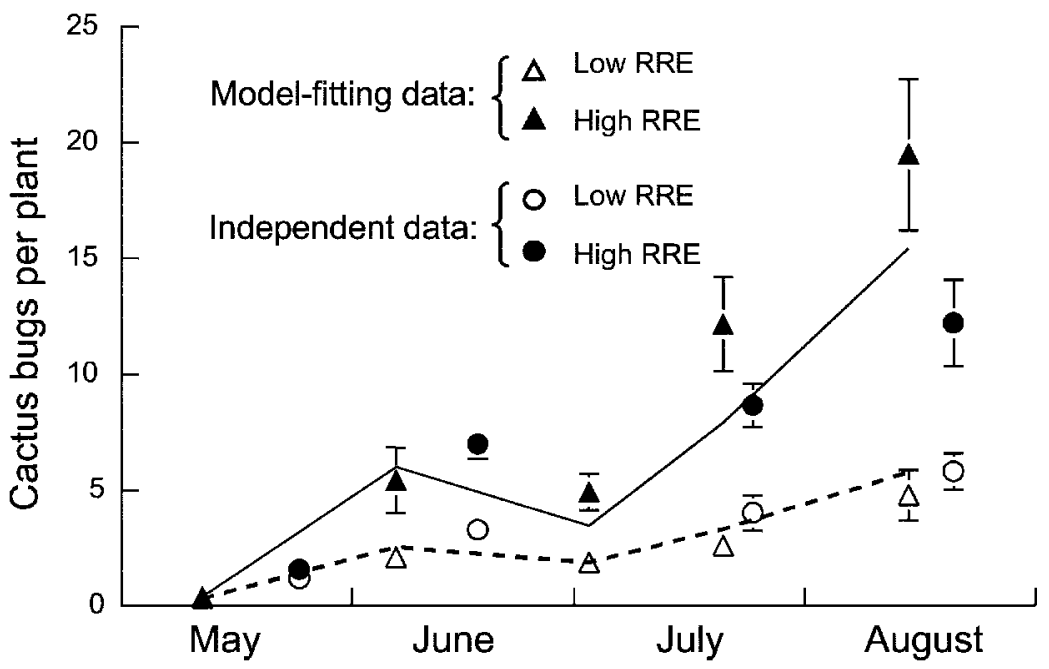

Figure 1: Projections of Narnia abundance (juvenile + adult) using the Akaike's Information Criterion-selected model structure (table 1, model 13) and parameter estimates (table 2). Lines represent predicted abundances. Triangles represent data used to fit the model, and circles represent independent data. Each data set is split into low relative reproductive effort (RRE; dashed line, open symbols) and high RRE (solid line, filled symbols) according to the median RRE value of each data set (median values of model fitting and independent data sets were 0.36 and 0.37 , respectively). Points represent averages of plants greater or less than the median. Predictions were based on average low RRE (0.17) and average high RRE (0.53).

note that while the independent data support the qualitative predictions of the model, they provide no information about underlying mechanisms. Thus, we do not know whether other demographic parameters (e.g., migration, survival) or other functional forms of fecundity drive these patterns across years and sites. In fact, neither the cross-year nor the cross-site insect-RRE relationship approximates a 0 intercept (as our single-year site model does), suggesting that other processes may operate at larger scales.

While multiple factors will contribute to variation in the abundance of specialist insect herbivores across time and space, our analyses strongly suggest that host plant resource allocation pattern is important. We conducted identical model fitting analyses in which RRE was replaced with other plant measures (age, size, number of reproductive structures) and found that RRE had the most predictive ability (see app. B in the online edition of the American Naturalist). We also examined differences in winter climate to explain interannual variation. However, differences in climate are unlikely to directly account for the increase in Narnia abundance during this study because sizes of the first cohort were similar across years (fig. $2 A$ ), suggesting that rates of overwinter survival were also similar across years. The results to date strongly suggest the potential for host-driven insect dynamics in this system.

If host plant resource allocation plays a significant role in herbivore dynamics, then identifying the factors that influence plant allocation becomes important for understanding the processes that ultimately drive variation in herbivore population densities. Relative allocation of meristems toward reproduction generally increases with cactus age, but it is unlikely that age can explain the variation in allocation strategies that we observed. The increases in RRE across years at the Sevilleta (fig. $2 A$ ) were greater than expected based on a 1-year increase in age (T. E. X. Miller, unpublished data). Across sites, mean plant age differed significantly between only two of our survey cactus populations (Aguirre Springs [8.9 years] vs. Sandia National Forest [11.0 years]; protected least significant difference test: $P=.023)$, and the younger population had greater RRE (fig. 2B). Winter precipitation could also be an important factor in tree cholla resource allocation because it is known to influence other components of cactus performance during the growing season (Bowers 1996; Pimienta-Barrios and del Castillo 2002). The observed increase in tree cholla RRE across years was associated with increases in winter precipitation in central New Mexico (New Mexico Climate Center, http://weather.nmsu.edu). However, Bowers (1996), studying another Opuntia species (Opuntia engelmannii) in the Sonoran Desert, found no relationship between winter precipitation and meristem allocation. Rather, she suggested that cacti maximize their fitness by alternating periods of high reproductive effort with periods of mostly vegetative growth, although no physiological mechanism for such switching has been identified (Bowers 1996). The interaction of genetic and en- 

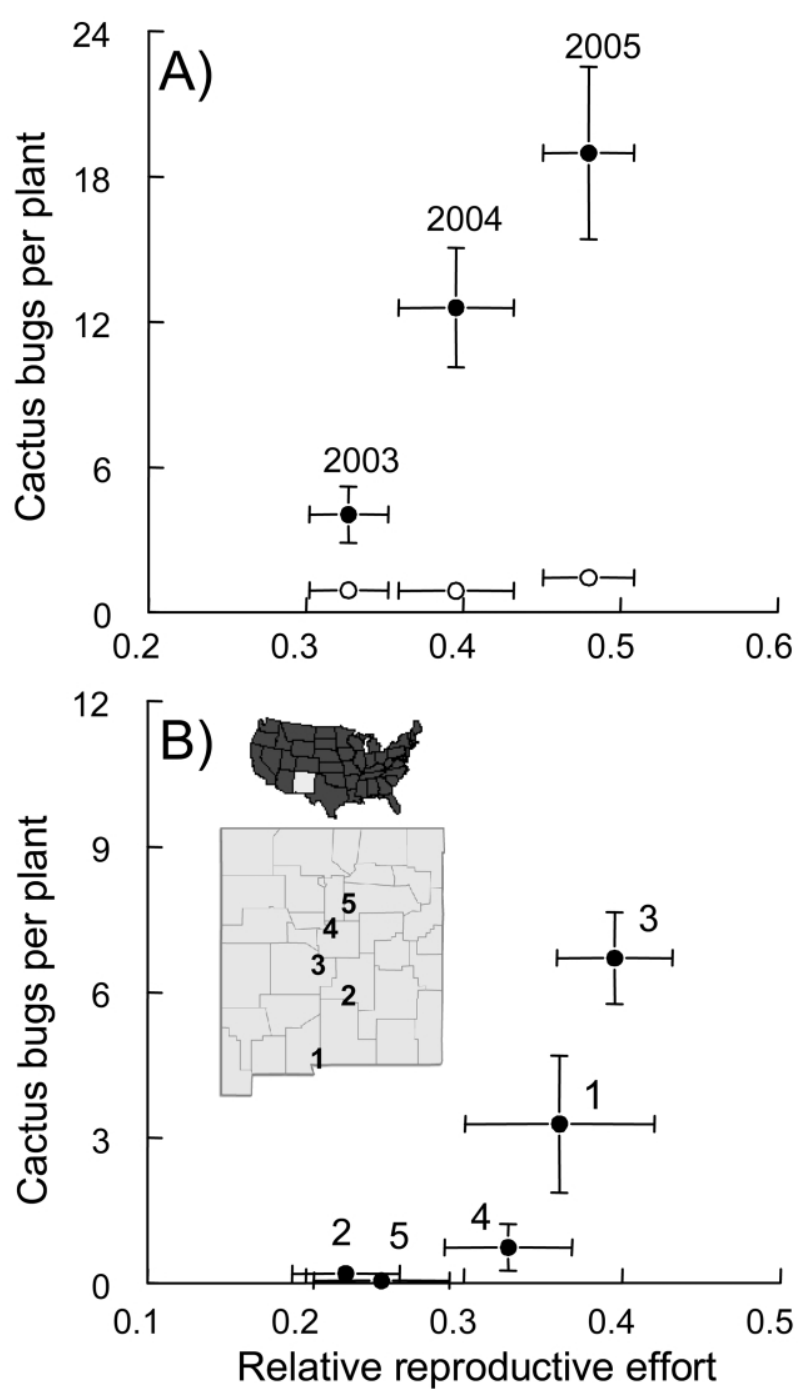

Figure 2: $A$, Temporal variation in tree cholla relative reproductive effort (RRE) and cactus bug abundance at the Sevilleta. Tree cholla RRE increased significantly from 2003 to 2005 (variation along the $X$-axis: $F=5.39, \mathrm{df}=2,138, P=.0055)$. This increase was associated with an increase in Narnia abundance that was greater for the late-season cohort (filled circles) than for the early-season cohort (open circles; variation along the $Y$-axis: cohort $\times$ year, $F=10.67, \mathrm{df}=2,269, P<.0001) . B$, Spatial variation in cactus RRE and Narnia abundance (correlation analysis using raw data points: $r=0.42, P<.001, n=124)$. Numbers next to data points correspond to sites on map. Points in both figures are mean \pm SE.

vironmental factors in plant resource allocation continues to be an area of active research (Bazzaz and Grace 1997; Vuorisalo and Mutikainen 1999).

Finally, on the basis of the strength and consistency of the modeling and empirical results, we suggest that future work on the evolution and maintenance of plant lifehistory strategies should consider the ecological conse- quences of resource allocation for interactions with other trophic levels. Costs of reproduction are central to plant life-history theory (Harper 1977), and accurately quantifying these costs is important for understanding the selective advantages of alternative allocation strategies (Reekie 1999). It is well established that current reproduction in plants can have negative effects on future survival and fecundity, and theories of allocation trade-offs are based almost exclusively on these resource-based costs (Obeso 2002). However, a strictly resource-based perspective may be insufficient to predict and explain plant life-history strategies.

We found that patterns of resource allocation between life-history functions had consequences for the abundance and dynamics of plant antagonists. Increasing the relative investment of meristems in reproduction led to an increase in the frequency of interactions with specialist herbivores. Thus, in addition to resource-based costs, plant reproductive effort may also incur herbivore-mediated ecological costs. This component of reproductive costs is typically neglected (Klinkhamer et al. 1997; Holland et al. 2004), and the generality of a positive relationship between plant reproduction and susceptibility to herbivores remains unknown (Obeso 2002). Given that herbivores can reduce plant fitness (Crawley 1983, 1997; Doak 1992; Louda and Potvin 1995; Bigger and Marvier 1998; Maron 1998; Ehrlen 2003), explicit consideration of the ecological costs of reproduction is needed to refine our understanding of optimal life-history strategies in plants.

\section{Acknowledgments}

We gratefully acknowledge the faculty and staffs of the Sevilleta long-term ecological research (LTER) site, especially S. Collins and J. Johnson, and the Sevilleta National Wildlife Refuge, especially D. Pritchard and R. Robichaud, for providing logistical support and a stimulating research environment. B. Inouye provided helpful discussion on the theory and practice of the model fitting approach. The suggestions of J. Eckberg, E. Gering, K. Keeler, C. Mitra, J. Stiver, and two anonymous reviewers greatly improved this work and manuscript. Funding for this work was provided by grants to T.E.X.M. from the Sevilleta LTER (National Science Foundation grant DEB-0217774) and the University of Nebraska's School of Biological Sciences and Initiative for Ecological and Evolutionary Analysis. T.E.X.M. was supported by a Graduate Assistance in Areas of National Need fellowship in environmental science from the U.S. Department of Education.

\section{Literature Cited}

Agrawal, A. A. 2004. Plant defense and density dependence in the population growth of herbivores. American Naturalist 164:113120. 
Bazzaz, F., and J. Grace. 1997. Plant resource allocation. Academic Press, San Diego, CA.

Benson, L. 1982. Cacti of the United States and Mexico. Stanford University Press, Stanford, CA.

Bigger, D. S., and M. A. Marvier. 1998. How different would a world without herbivory be? a search for generality in ecology. Integrated Biology 1:60-67.

Bonser, S. P., and L. W. Aarssen. 1996. Meristem allocation: a new classification theory for adaptive strategies in herbaceous plants. Oikos 77:347-352.

Bowers, J. E. 1996. More flowers or new cladodes? environmental correlates and biological consequences of sexual reproduction in a Sonoran Desert prickly pear cactus, Opuntia engelmannii. Bulletin of the Torrey Botanical Club 123:34-40.

Bradley, K. L., E. I. Damschen, L. M. Young, D. Duefler, S. Went, G. Wray, N. M. Haddad, J. M. H. Knops, and S. M. Louda. 2003. Spatial heterogeneity, not visitation bias, dominates variation in herbivory. Ecology 84:2214-2221.

Burnham, K. P., and D. R. Anderson. 1998. Model selection and multi-model inference: a practical information-theoretic approach. Springer, New York.

Crawley, M. J. 1983. Herbivory: the dynamics of animal-plant interactions. University of California Press, Berkeley.

1997. Plant-herbivore dynamics. Pages 401-474 in M. J. Crawley, ed. Plant ecology. Blackwell Science, Oxford.

Denno, R. F., and M. S. McClure. 1983. Variable plants and herbivores in natural and managed systems. Academic Press, New York.

Doak, D. F. 1992. Lifetime impacts of herbivory for a perennial plant. Ecology 73:2086-2099.

Duffy, N. M., S. P. Bosner, and L. W. Aarssen. 1999. Patterns of variation in meristem allocation across genotypes and species in monocarpic Brassicaceae. Oikos 84:284-292.

Edelstein-Keshet, L., and M. D. Rausher. 1989. The effects of inducible plant defenses on herbivore populations. 1. Mobile herbivores in continuous time. American Naturalist 133:787-810.

Ehrlen, J. 2003. Fitness components versus total demographic effects: evaluating herbivore impacts on a perennial herb. American Naturalist 162:796-810.

Geber, M. A. 1990. The cost of meristem limitation in Polygonum arenastrum: negative genetic correlations between fecundity and growth. Evolution 44:799-819.

Geber, M. A., M. A. Watson, and H. de Kroon. 1997. Organ preformation, development, and resource allocation in perennials. Pages 113-142 in F. Bazzaz and J. Grace, eds. Plant resource allocation. Academic Press, San Diego, CA.

Gibson, A. C., and P. S. Nobel. 1986. The cactus primer. Harvard University Press, Cambridge, MA.

Harper, J. L. 1977. The population biology of plants. Academic Press, New York.

Hartemink, M., E. Jongejans, and H. de Kroon. 2004. Flexible life history responses to flower and rosette bud removal in three perennial herbs. Oikos 105:159-167.

Hilborn, R., and M. Mangel. 1997. The ecological detective: confronting models with data. Princeton University Press, Princeton, NJ.

Holland, J. N., D. L. DeAngelis, and S. T. Schultz. 2004. Evolutionary stability of mutualism: interspecific population regulation as an evolutionarily stable strategy. Proceedings of the Royal Society B: Biological Sciences 271:1807-1814.

Huberty, A. F., and R. F. Denno. 2004. Plant water stress and its consequences for hebivorous insects: a new synthesis. Ecology 85: 1383-1398.

Kinraide, T. B. 1978. The ecological distribution of cholla cactus (Opuntia imbricata (Haw.) DC) in El Paso County, Colorado. Southwestern Naturalist 23:117-134.

Klinkhamer, P. G. L., T. Kubo, and Y. Iwasa. 1997. Herbivores and the evolution of the semelparous perennial life-history of plants. Journal of Evolutionary Biology 10:529-550.

Larsson, S., B. Ekbom, and C. Bjorkman. 2000. Influence of plant quality on pine sawfly population dynamics. Oikos 89:440-450.

Louda, S. M. 1982. Distribution ecology: variation in plant recruitment in relation to insect seed predation. Ecological Monographs 52:25-41.

- 1983. Seed predation and seedling mortality in the recruitment of a shrub, Haplopappus venetus (Asteraceae), along a climatic gradient. Ecology 64:511-521.

Louda, S. M., and S. K. Collinge. 1992. Plant resistance to insect herbivores: a field test of the environmental stress hypothesis. Ecology 73:153-169.

Louda, S. M., and M. A. Potvin. 1995. Effect of inflorescence-feeding insects in the demography and lifetime fitness of a native plant. Ecology 76:229-245.

Mann, J. 1969. Cactus-feeding insects and mites. Smithsonian Institution, Washington, DC.

. 1970. Cacti naturalized in Australia and their control. Government Printer, Brisbane.

Maron, J. L. 1998. Insect herbivory above- and belowground: individual and joint effects on plant fitness. Ecology 79:1281-1293.

Mendez, M., and P. S. Karlsson. 2004. Between-population variation in size-dependent reproduction and reproductive allocation in Pinguicula vulgaris (Lentibulariaceae) and its environmental correlates. Oikos 104:59-70.

Obeso, J. R. 2002. The costs of reproduction in plants. New Phytologist 155:321-348.

Olejniczak, P. 2001. Evolutionary stable allocation to vegetative and sexual reproduction in plants. Oikos 95:156-160.

Pimienta-Barrios, E., and R. F. del Castillo. 2002. Reproductive biology. Pages 75-90 in P. S. Nobel, ed. Cacti: biology and uses. University of California Press, Berkeley.

Prado, P. I. K. L., and E. M. Vieira. 1999. The interplay between plant traits and herbivore attack: a study of a stem galling midge in the Neotropics. Ecological Entomology 24:80-88.

Rausher, M. D. 1981. Host plant selection by Battus philenor butterflies: the roles of predation, nutrition and plant chemistry. Ecological Monographs 51:1-20.

Reekie, E. G. 1999. Resource allocation, trade-offs, and reproductive effort in plants. Pages 173-194 in T. O. Vuorisalo and P. K. Mutikainen, eds. Life history evolution in plants. Kluwer Academic, Dordrecht.

Rhoades, D. F. 1983. Herbivore population dynamics and plant chemistry. Pages 55-68 in R. F. Denno and M. S. McClure, eds. Variable plants and herbivores in natural and managed systems. Academic Press, New York.

Root, R. B. 1996. Herbivore pressure on goldenrods (Solidago altissima): its variation and cumulative effects. Ecology 77:1074-1087.

Root, R. B., and N. Cappuccino. 1992. Patterns in population change and the organization of the insect community associate with goldenrod, Solidago altissima. Ecological Monographs 62:393-420.

Silvertown, J., and M. Dodd. 1999. The demographic cost of repro- 


\section{The American Naturalist}

duction and its consequences in balsam fir (Abies balsamea). American Naturalist 29:321-332.

Underwood, N., and M. D. Rausher. 2000. The effects of host plant genotype on herbivore population dynamics. Ecology 81:15651576.

Vuorisalo, T., and P. Mutikainen, eds. 1999. Life history evolution in plants. Kluwer Academic, Dordrecht.

Watson, M. A. 1984. Developmental constraints: effect on population growth and patterns of resource allocation in a clonal plant. American Naturalist 123:411-426.

White, T. C. R. 1984. The abundance of invertebrate herbivores in relation to the availability of nitrogen in stressed food plants. Oecologia (Berlin) 63:90-105.

Associate Editor: William F. Morris Editor: Donald L. DeAngelis 